REPORT

\title{
Faculty Collaboration and Technology in the Liberal Arts: Lessons from a Teagle Grant Program
}

January 29, 2018

Martin Kurzweil

Daniel Rossman

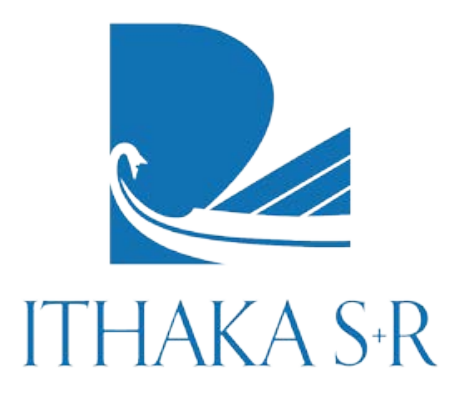




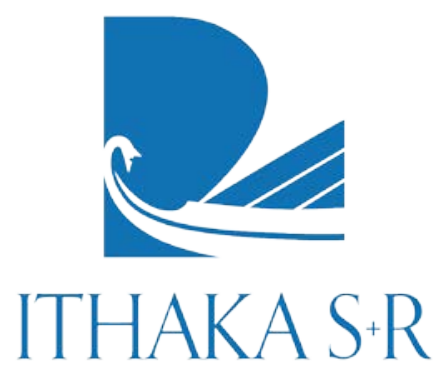

Ithaka S+R provides research and strategic guidance to help the academic and cultural communities serve the public good and navigate economic, demographic, and technological change. Ithaka $\mathrm{S}+\mathrm{R}$ is part of ITHAKA, a not-for-profit organization that works to advance and preserve knowledge and to improve teaching and learning through the use of digital technologies. Artstor, J STOR, and Portico are also part of ITHAKA.

Copyright 2018 ITHAKA. This work is licensed under a Creative Commons Attribution-NonCommercial 4.0

International License. To view a copy of the license, please see http://creativecommons.org/licenses/by-nc/4.0/.

ITHAKA is interested in disseminating this brief as widely as possible. Please contact us with any questions about using the report: research@ithaka.org. 


\section{ITHAKA S.R}

\section{Executive Summary}

In response to enrollment and revenue declines, residential liberal arts programs are seeking ways to contain costs and build institutional capacity, while maintaining the quality of a liberal arts education. Some institutions have banded together to form robust consortia to share resources and distribute burdens. And some of these consortia have focused their efforts on the creation and use of online teaching resources and courses, hypothesizing that doing so will increase institutional capacity to provide educational offerings at a fraction of the cost of duplicating those offerings at each institution.

The Teagle Foundation's "Hybrid Learning and the Residential Liberal Arts Experience” program, which ran from 2014 to 2016, funded a group of higher education consortia to test whether the collaborative development of technology-enhanced educational resources can cost-effectively increase institutional capacity to offer high-quality learning experiences. Ithaka S+R has observed and assessed the grant program on behalf of Teagle since the program's launch. Our assessment-based on instructor surveys, interviews with instructors and consortia staff, and review of grantees' reports-has yielded a number of lessons regarding faculty collaboration within and across institutions, the value of instructional technology in liberal arts education, and the conditions for building institutional capacity through collaboration and technology.

Faculty collaboration in creating new educational resources that rely on technology can serve as a catalyst for rethinking pedagogy, and has the potential to be a cost-effective means by which liberal arts colleges can provide more students high-quality learning experiences that are in line with the core tenets of a liberal arts education. Despite the time-consuming and difficult nature of incorporating technology into course creation, faculty were appreciative of the time they spent collaborating with peers. As we heard from numerous faculty, both the collaboration and the challenge of conceptualizing an academic experience in a different modality provided new insights into their pedagogy. But another important lesson of the Teagle project is that fully realizing the benefits of collaborative course design requires a lot of support-from the leadership and administrative staff of faculty members' home institutions and from a backbone organization with the resources and infrastructure to coordinate across institutions and strategically plan how to share courses. 


\section{ITHAKA S.R}

\section{Introduction}

Over each of the past five years, the total number of undergraduate students in the United States has declined. ${ }^{1}$ There are multiple potential reasons for this trend: rising tuition, questions about the value of a postsecondary education, and shifting demographics have all likely contributed. While the impact of this trend has been felt across higher education institutions, private liberal arts colleges have been hit particularly hard, ${ }^{2}$ as have liberal arts programs offered at public institutions, marked by a decline in enrollment in colleges of arts and sciences within universities. ${ }^{3}$ List tuition at many small, private colleges is well above $\$ 50,000$ - at a time when students are becoming increasingly cost-conscious. In addition, potential applicants and enrollees of all types of institutions are questioning whether a liberal arts education will provide them the skills to succeed in an increasingly competitive and challenging labor market once they graduate.

To combat this trend, these mostly-tuition-dependent institutions have turned to a number of strategies to increase enrollment and hold down costs, without sacrificing program quality, including offering more institutional grant aid (also known as raising the discount rate) to lower the price students actually pay. For colleges with modest endowments, however, high discount rates are not financially sustainable. Recent analyses, including one conducted by the National Association of College and University Business Officers (NACUBO), found that the changing demographics and financial difficulties faced by students are not expected to change in the near future, suggesting the need for a long-term solution. ${ }^{4}$

To make a lower net price for students more sustainable, liberal arts programs are also trying to address the cost of providing education. Many of these institutions have, for some time, shared administrative services and resources and distributed burdens with other local or otherwise affiliated institutions. Some of these efforts have spawned robust

\footnotetext{
1 "Total Fall Enrollment in Degree-Granting Postsecondary Institutions, By Level of Enrollment, Sex, Attendance Status, and Race/Ethnicity of Student: Selected Years, 1976 through 2015," National Center for Education Statistics, https://nces.ed.gov/programs/digest/d16/tables/dt16 306.10.asp.

2 Jon Marcus, "Many Small Colleges Face Big Enrollment Drops. Here's One Survival Strategy in Ohio," The Washington Post, June 29, 2017, https://www.washingtonpost.com/news/grade-point/wp/2017/06/29/many-small-colleges-face-big-enrollment-drops-heresone-survival-strategy-in-ohio/?utm term $=.2$ dd199127636.

${ }^{3}$ Kellie Woodhouse, "Arts and Sciences Deficits," Inside Higher Ed, June 4, 2015, https://www.insidehighered.com/news/2015/06/04/colleges-arts-and-sciences-struggle-deficits-enrollment-declines.

${ }^{4}$ Rick Seltzer, "Discounting Keeps Climbing," Inside Higher Ed, May 15, 2017, https://www.insidehighered.com/news/2017/05/15/private-colleges-and-universities-increase-tuition-discounting-again-2016-17.
} 


\section{ITHAKA S.R}

consortia that provide infrastructure and facilitate collaboration in other ways, as well. More recently, a number of these institutional consortia have focused their efforts on the creation and use of online teaching resources and courses. In theory, such shared courses and resources increase institutional capacity to provide educational offerings at a fraction of the cost of duplicating those offerings at each institution. The worry, typically, is that educational quality will suffer.

\section{The Teagle Foundation's "Hybrid Learning and the Residential Liberal Arts Experience" Program}

In 2014-2016, the Teagle Foundation funded a group of higher education consortia to test the hypothesis that collaborative development of technology-enhanced educational resources can cost-effectively increase institutional capacity to offer high-quality learning experiences. The Foundation's goals for the project were to:

- Identify and support models to integrate online education into the residential liberal arts experience in ways that speak to both the quality of student learning and questions of institutional capacity;

- Encourage the formation of communities of practice from multiple institutions; and

- Create a knowledge base of concepts and strategies related to hybrid learning in liberal arts institutions that can be shared with others.

Eight groups of higher education institutions were awarded grants: the American Association of State Colleges and Universities (AASCU), the Council of Public Liberal Arts Colleges (COPLAC), Five Colleges, Inc., the Lehigh Valley Association of Independent Colleges (LVAIC), the Midwest Hybrid Learning Consortium (MHLC), the Texas Language Consortium (TLC), and two teams of colleges led by Bryn Mawr College and St. Norbert College respectively. Summaries of these projects, including the number of courses or modules created and the number of faculty and staff involved, are in the Appendix, below.

At the outset, the Teagle Foundation hired Ithaka S+R to assess the grant program, offering us a front-row view of these efforts as they have progressed. Reflecting on the grant program as it winds down, our assessment-based on instructor surveys, interviews with instructors and consortia staff, and review of grantees' reports-has yielded a number of lessons regarding faculty collaboration within and across institutions, the value of instructional technology in liberal arts education, and the conditions for building institutional capacity through collaboration and technology. We summarize those lessons below, based on our assessment and featuring topical quotes from the surveys of participating faculty. 


\title{
ITHAKA S.R
}

\section{Faculty Collaboration}

Faculty appreciate the opportunity to collaborate with colleagues on instructional design. Participating faculty members consistently reported that having the opportunity to work with colleagues within and across their institutions on course design was a valuable - and rare-experience. While some faculty recalled initial wariness about the additional burden such collaborative work would require, most came away from the experience believing they had learned something new about course structure and pedagogy, and had improved their teaching ability as a result. Beyond their own collaborative project work, participating faculty valued opportunities to share best practices and lessons learned; exchange information and ideas; and network with faculty across projects and consortia. Faculty members particularly valued opportunities to engage with colleagues face-to-face, citing such contact as important for building trust. Many pointed to an April 2016 Teagle-hosted convening of grant program participants and instructional technology experts as an exemplar of this kind of engagement.

\section{Faculty collaboration can reduce the burden of developing instructional}

technology resources. While the coordination challenges of involving multiple faculty members have the potential to increase the burden of technology development, faculty participating in the Teagle projects found that the collaboration, in fact, reduced the overall burden on each participant. Sharing the work not only allowed faculty to divide tasks that a single faculty member would otherwise have had to handle on their own, some reported that it also allowed partners to specialize in areas in which they had the most expertise. For instance, TLC created a curriculum development team with representatives from each campus that met monthly or bimonthly while assessment, technology, and pedagogy teams met monthly. As part of AASCU's project, multiple faculty members worked on creating course content and enlisted a team of instructional designers to handle all of the technical work related to building course materials in the online platform.

"I benefitted a great deal from the opportunity to participate in this Teagle project. I found it very helpful to work with a colleague at another institution, and I believe that we will continue to interact and possibly collaborate in the future again. I also benefitted from hearing what others in the group did for their projects."

- Faculty Member, MHLC Project

\begin{abstract}
A backbone organization can bolster faculty collaboration across institutions, and provide valuable administrative support. Coordinating work across faculty located on different campuses can take considerable effort and
\end{abstract}




\section{ITHAKA S.R}

infrastructure. Furthermore, technology projects typically require administrative tasks like engaging technical experts, contracting with vendors, and managing maintenance, which may be challenging for one small institution to manage for itself; the complexity of managing these tasks across multiple institutions is much greater. Participants in the Teagle program that were supported by a robust, fully staffed consortium or association were able to navigate these barriers to collaboration more effectively. Most projects relied on an online platform to serve as a hub of information and a place to share resources and materials, like MyOpenMath or TeamWork. Others hosted in-person faculty development workshops and trainings.

Beyond facilitating communication among faculty, consortia provide other valuable services. For example, Five Colleges managed the process of sharing equipment purchased as part of the initiative, as well as developed an intellectual property policy to support sharing and modifying of resources for educational use, as did AASCU and St. Norbert and its campus partners. Consortia also took responsibility for forming project teams with representatives from each participating campus and ensuring that technical experts, like instructional technologists, designers, and IT staff, were accessible.

\section{Value of Technology in Liberal Arts Education}

\section{Technology can create more opportunities for discussion and application of}

concepts. Engaged dialogue among students and faculty in an intimate setting is a hallmark of a liberal arts education. The conventional wisdom is that technologyenhanced courses limit or eliminate opportunities for this kind of engagement. Participants in the Teagle program generally found the opposite to be true. While some projects offered courses entirely online, most projects either used flipped classrooms, in which some instructional content was delivered online and supplemented by face-to-face meetings, or incorporated modules and online videos into their courses. In those hybrid models, in which students learned foundational concepts primarily outside the classroom, faculty reported that students typically had more opportunity during class for in-depth discussion and application. Some faculty also reported that students' participation in online discussions allowed less-outgoing students greater opportunities to participate, and better-enabled faculty members to get to know them as individuals, as compared to a traditional face-to-face setting. In addition to student engagement, the vast majority of faculty were satisfied with the level of student learning, reporting that the depth and breadth of student learning were either greater than or about the same as the depth and breadth of student learning in analogous, traditionally taught courses. Notably, however, faculty who worked on fully online courses felt that important aspects of the liberal arts learning experience were not replicable, noting in particular that it was easier for students to become disengaged. Most of these faculty indicated they would pursue a hybrid model if they were to attempt another course re-design. In fact, one 


\section{ITHAKA S.R}

course initially offered entirely online by members of the LVAIC consortium will be offered in spring 2018 as a hybrid course, with some face-to-face interaction incorporated in hopes of improving student learning.

"I have been continually surprised and pleased by the ways in which the hybrid format really facilitates deep and thoughtful work when used in conjunction with FTF [face-to-face] instruction. I am continually impressed by the ways in which discussions expand and develop for several days, with increased engagement with a range of outside sources."

- Faculty Member, MHLC Project

Technology can increase access to liberal arts education, and the diversity of those who access it. Online courses offered across multiple campuses enable students to take courses they normally would not have the opportunity to if offered in a traditional face-to-face manner. Beyond increasing course access, enrolling students remotely from a variety of institutions is likely to diversify the student makeup of the classroom as well as the classroom discussion. Many participating faculty cited access and diversity as core tenets of a liberal arts education, and saw their efforts in online and hybrid learning as supporting that aspect of the mission. For example, one of COPLAC's faculty teams developed a hybrid course in Native American Studies that enrolled students from a predominantly white institution and students from an institution with a large Native American population. The course enabled its participants to engage on the subject with students they ordinarily would not encounter in a similar class on their own campus, gaining new insights from the diverse perspectives represented.

"I was most satisfied by teaching in an online/ hybrid format that brought students together from different campuses and locations, and seeing how that diversity enhanced the course. It was also quite satisfying to see every single student's voice equally represented in the online/ hybrid format, as opposed to the traditional classroom discussion where not all students participate on a day-to-day basis."

- Faculty Member, COPLAC Project

Incorporating technology into a course is time-consuming and resourcedemanding, and many faculty face a learning curve. For many participating faculty, the Teagle project was their first effort to develop a technology-enhanced course or resource. Not surprisingly, many reported that the time and effort required to 


\section{ITHAKA S.R}

incorporate technological modifications exceeded the time and effort spent on developing a comparable face-to-face course. Indeed, when surveyed about how much time it took them to plan and develop the Teagle-funded course relative to a comparable face-to-face course, 100 percent of respondents answered about the same time or greater, including 80 percent who answered more time or much more time. In addition to technical challenges, faculty members faced a learning curve in conceptualizing how they would structure the learning process and translate content to an online format.

\section{Exposure to instructional technology improves faculty members' attitudes}

about it. Interestingly, despite the intensive effort and other challenges reported by most faculty, participation in the project generally resulted in faculty having a more favorable view of instructional technology than when they started. For many faculty, this shift in attitude was not driven by the value of the technology itself. Rather, the effort to incorporate technology or design a course with technology forced faculty to reflect on course structure and their pedagogy in a way they rarely had the opportunity to do. As one participant noted, technology makes one think about a course differently, in a productive way. Others cited the collaborative nature of the project as important to their view of technology: talking through the benefits and challenges of the technology with an engaged peer provided a new and more positive, problem-solving perspective.

"I would encourage my peers to engage in hybrid/ online teaching because it not only benefits the students, but also the faculty members who participate in this additional mode of teaching and learning!"

- Faculty Member, LVAIC Project

\section{Building Institutional Capacity}

Even if you build it, students may not come. While most faculty were pleased with the course or resource they created through the Teagle program, faculty satisfaction did not generally translate into high student enrollment. Course enrollment was typically no higher than for a similar face-to-face course: when asked to compare the number of students who enrolled compared to the typical enrollment for a course of this nature at their institution, more than three-fourths answered about the same number of students while less than a fifth answered fewer students and only 4 percent answered more students. These enrollment patterns may in part be a result of the choice of subject or course design: when asked about the extent to which their courses could scale, faculty on average reported they could handle a maximum enrollment of 29, with 20 being the most common response. Another limitation is students' hesitancy-or administrative barriers-to taking courses offered by faculty outside their home institutions. A large majority of faculty members reported that at least three-fourths of the students enrolled 


\section{ITHAKA S.R}

in their courses were from the home institution. Focusing on a course with steady enrollment, offered by many of the partner institutions, seems to help. For example, Bryn Mawr and its campus partners developed online instructional materials and modules to support courses in psychology research methods and statistics offered at each of the participating colleges.

\section{Building institutional capacity-and even successful implementation- requires a broader institutional commitment. One overarching lesson from the} Teagle project is that faculty collaboration in technology-enhanced course development requires significant institutional support. While faculty generally benefitted from the facilitation and resources provided by consortia, most relied heavily on their own institutions' IT staff and teaching and learning resources as well. More significantly, developing new courses and resources alone is unlikely to result in a sustainable increase in institutional capacity. Broader institutional changes are required to have an impact. Senior administrators must be actively engaged to eliminate potential administrative barriers and develop a sustainable business model. Registrars must collaborate across institutions to ensure that courses qualify for credit toward students' degrees at their home institutions. Something as mundane as a failure to update the course catalog can undermine an effort, as one grantee learned when only one student enrolled in one of the three courses offered.

\section{Incorporating new technology-based courses and resources into existing} cross-institutional programs encourages administrator, faculty, and student participation. Several participating consortia were able to enhance the buy-in of faculty and administrators, and put their projects on the path to sustainability, by leveraging existing cross-institutional curricular work. The LVAIC group's course on "Documentary Practice" was designed as a required component of a joint minor in documentary studies that students can only complete by cross-registering at multiple consortium institutions. Students from three different institutions participated in the course in 2016-17 and the course is already scheduled to be offered in spring 2018. Similarly, with support from the Mellon Foundation, the Five Colleges team is incorporating the modules it created through the Teagle grant into a hybrid course that will be a key component of a new consortium-wide certificate program in digital humanities. 


\section{ITHAKA S+R}

\section{Conclusion}

Residential liberal arts programs are going through a tumultuous stretch. To keep up with changing circumstances, many are proactively seeking new ways of operating that preserve the most valuable elements of the liberal arts experience, while holding down costs and building institutional capacity. Based on our three-year observation of the Teagle Foundation's "Hybrid Learning and the Residential Liberal Arts Experience" grant program, we believe that structured collaboration among faculty and institutions to redesign academic offerings with technology has real potential to help these institutions thrive in the future. By sharing the burden and benefit of creating new educational resources that rely on technology to increase student access, both faculty and institutions can provide more students high-quality learning experiences. As we heard from numerous faculty, both the collaboration with peers and the challenge of conceptualizing an academic experience in a different modality provided new insights into their pedagogy. But another important lesson of the Teagle project is that fully realizing the benefits of collaborative course design requires a lot of support-from the leadership and administrative staff of faculty members' home institutions and from a backbone organization with the resources and infrastructure to coordinate across institutions. Liberal arts colleges and programs that commit to working together to support this kind of faculty innovation will be in a better position to navigate the uncertain road ahead. 


\section{ITHAKA S+R}

\section{Appendix}

\section{Number of revised or created courses and modules that have been offered, and number of staff that have played role in course development or teaching ${ }^{5}$}

\begin{tabular}{llll} 
& Number of courses $^{6}$ & Number of modules $^{7}$ & Number of staff8 $^{8}$ \\
\hline AASCU & $4^{9}$ & 0 & 20 \\
\hline Bryn Mawr & 0 & 19 & 13 \\
\hline COPLAC & 14 & 0 & 13 \\
\hline Five Colleges & 7 & 0 & 36 \\
\hline LVAIC & 10 & 45 & 36 \\
\hline MHLC & 23 & 25 & 21 \\
\hline St. Norbert College & 0 & 11 & 30 \\
\hline TLC & 22 & 0 & 25 \\
\hline
\end{tabular}

${ }^{5}$ Totals are accurate as of when each grantee submitted their 2017 annual report to the Teagle Foundation, mostly between June and August 2017. The grants have different start/end dates, with three projects - those managed by AASCU, COPLAC, and LVAIC - still in progress as of this report and ending in either spring, summer, or winter 2018.

${ }^{6}$ Total number of newly revised or created courses that have been offered since the project launched to date.

${ }^{7}$ Total number of modules that have been created since the project launched to date.

${ }^{8}$ Total number of faculty and staff (including lecturers, part-time adjuncts, instructional designers, and teaching assistants) that have played a role in developing and/or teaching courses.

${ }^{9}$ The institutions participating in the AASCU project will launch their four newly-created courses in summer or fall 2018. 


\section{ITHAKA S+R}

\section{Brief descriptions of each project}

- AASCU created the National Blended Course Consortium, an initiative aimed at addressing "three pressing issues in higher education-cost, access, and quality-through the development and dissemination of technology-enhanced, interdisciplinary courses for first-year undergraduates." "National Blended Course Consortium," The Teagle Foundation, http:// www.teaglefoundation.org/Grants-Initiatives/GrantsDatabase/Grants/Hybrid-Learning/National-Blended-Course-Consortium.

- Bryn Mawr College and its campus partners Albright College, College of St. Benedict and St. J ohn's University, Saint Mary's College of California, Santa Rose J unior College, Swarthmore College, and Wesleyan University developed online instructional materials and modules to support teaching related to psychology research methods and statistics, and worked on creating a model for collaborative development that faculty in other disciplines may be able to adopt. "Modeling Collaborative Curriculum Development: Psychology Research Methods and Statistics," The Teagle Foundation, http:// www.teaglefoundation.org/Grants-Initiatives/Grants-Database/ Grants/HybridLearning/Modeling-Collaborative-Curriculum-Development-Psy.

- COPLAC's project, formed by six public liberal arts institutions, all with a tradition of serving Native American students and offering courses in that field, worked to develop (or modify) several courses in Native American Studies offered in hybrid form to students across their institutions. "Hybrid Course Sharing in Native American Studies," The Teagle Foundation, http:// www.teaglefoundation.org/Grants-Initiatives/ GrantsDatabase/ Grants/Hybrid-Learning/Hybrid-Course-Sharing-in-Native-American-Studies.

- Five Colleges, Inc.'s project, as part of their new Blended Learning Initiative, has sought to develop and test hybrid learning strategies and materials by multi-campus teams, through which they've launched four projects that have attempted to improve alreadycreated courses. "A Consortial Plan to Explore Hybrid Learning in the Residential Liberal Arts Institutions of Five Colleges, Incorporated," The Teagle Foundation, http:// www.teaglefoundation.org/ Grants-Initiatives/ Grants-Database/ Grants/ HybridLearning/A-Consortial-Plan-to-Explore-Hybrid-Learning-in-th.

- LVAIC's project is led by a core team comprised mostly of faculty from participating institutions that seeks to support cross-campus teams of faculty interested in developing and piloting online modules and courses. "Hybrid Course Sharing in the Lehigh Valley Association of Independent Colleges of Pennsylvania," The Teagle Foundation, http:// www.teaglefoundation.org/ Grants-Initiatives/Grants-Database/ Grants/HybridLearning/Hybrid-Course-Sharing-in-the-Lehigh-Valley-Associa.

- MHLC, a newly formed consortium consisting of institutions unfamiliar with hybrid learning, sought to hold workshop events to learn hybrid principles and methods and then develop hybrid modules and courses by faculty working in teams across all six institutions. "Hybrid Liberal Arts Network: High Touch Learning for the 21st Century," The Teagle Foundation, http:// www.teaglefoundation.org/ Grants-Initiatives/ GrantsDatabase/ Grants/Hybrid-Learning/Hybrid-Liberal-Arts-Network-High-Touch-Learningf. 


\section{ITHAKA S R}

- St. Norbert College and its campus partners Augustana College, Elmhurst College, and Illinois Wesleyan University focused on creating online modules in core competency areas through a collaborative, faculty-led process. "Launching an Online Competencies Curriculum," The Teagle Foundation, http:// www.teaglefoundation.org/GrantsInitiatives/Grants-Database/ Grants/Hybrid-Learning/Launching-an-OnlineCompetencies-Curriculum.

- TLC used the grant to operationalize and expand their program, which shares world language courses across five institutions through three project teams: assessment, technology and pedagogy teams. "Working Together in the Lone Star State: Operationalizing Blended Learning Programs in the Texas Language Consortium," The Teagle Foundation, http:// www.teaglefoundation.org/Grants-Initiatives/GrantsDatabase/ Grants/Hybrid-Learning/Working-Together-in-the-Lone-Star-StateOperation. 